\title{
Beyond Winning: Unlocking Entrenched Conflict Using Principles and Practices of Negotiation in the Mediation Room
}

\section{Margaret Considine}

\begin{abstract}
This article looks at the uses and application of the tools and tactics of negotiation in the mediation room. It explores how the art and practice of negotiation might be of practical use to skilled mediators as they assist parties to devise a solution they have worked for by effectively negotiating their way skilfully through the issues. Mediation is a profession, and understanding the dynamics of the dance of negotiation and how it affects the mindsets and actions of parties in a conflict can help mediators get behind the initial positions of parties, through effective dialogue to explore interests and to have the parties meet their needs without sacrificing the needs or goals of the other party. "Words and Concessions are the lubrication of negotiations" Prof. Robert Mnookin Head of the Program on Negotiation Harvard Law School.
\end{abstract}

\section{Keywords}

Conflict, negotiation, mediation, practice,

\section{Introduction}

Have you ever found yourself listening to your clients tell their story in mediation and think they are so locked in this conflict it will take Kofi Anan to move them? Did you every listen to your clients argue and think they are so far apart on the same issue that finding any form of common ground, or mutuality of interest, is going to be very difficult for you as mediator? If so, then a broad knowledge of the tools, skills and dynamics of the psychology of negotiation might just serve you well at those tough times. In this article I will simplify some of the dynamics of negotiation and show how they can be an advantage to a skilled and practiced mediator to generate more movement in entrenched conflicts towards a mutually acceptable solution for all sides. Mediation is when a neutral third party facilitates parties in dispute to have a difficult conversation and skilfully helps them find a resolution to their 
problems, in a safe and equitable way. It is process that facilitates communication and negotiation between the parties to the conflict and promotes voluntary decision making by the parties to prevent or resolve a dispute and to assist them to reach a mutually acceptable solution.

Mediation seeks to: resolve the conflict, change disputing behaviours, assist communication, improve understanding, facilitate negotiations, maintain parity between the parties, treat people fairly and make realistic workable agreements. In all of this, a thorough knowledge of the dynamics of negotiation can only help master the art of your professional practice as a skilled mediator.

\section{The Context of Negotiation}

"Faust complains about having two souls in his breast, but I harbour a whole crowd of them and they quarrel. It is like being in a republic" Otto Von Bismarck (Hoffman, D, A 2011).

Negotiation is a resolution method; to be negotiating one is already in conflict. Negotiation is the practice of trading where two or more parties have a joint difficulty and enter an interaction in an attempt to find an agreement. All negotiations involve three criteria - they involve price or something the parties' value, they involve movement or trading, and they involve relationships because they are conducted by people. This s o u n d s very similar to mediation doesn't it? Because one element of mediation involves negotiations among the parties.

Being in negotiations and negotiating are two different things. Suppose a tenant offers his landlord $€ 50,000$ to buy out the lease of the building. Are we negotiating? Technically no. This is a bid. A bid is an anchor, a figure or position once issued - placed in the domain of the dialogue -- cannot easily be withdrawn. It is only a negotiation when an anchor is also set down by the other party, i.e. the landlord wants $€ 75,000$. The parties are technically now in negotiations. However, it is worth noting that they are only 'negotiating' when a trade/movement from a position or anchor has occurred. With both anchors established, a major insight is evident. This 'line of difference' shows how far apart the parties are on this particular issue or variable [something that can go up or down in a negotiation]. In this case the negotiation is about $€ 25,000$, the gap between the two anchors. If this was the only issue in the negotiation, then this is the size of the table. If there were five more issues i.e. the date of vacating the premises, the return of a deposit, and the gap between both sides anchors on each of these gives the combined value of the negotiation, the full size of the table or the totality of what the parties are in conflict about. The chart below illustrates the nature of a negotiation based on multipleissues. 


\begin{tabular}{|c|c|c|c|c|}
\hline Issue & Party 1 & & Party 2 & Difference \\
\hline Lease Price & 75000 & & 50000 & 25000 \\
\hline $\begin{array}{l}\text { Date of } \\
\text { Vacating }\end{array}$ & $\begin{array}{l}\text { End } \\
\text { Q2 }\end{array}$ & & $\begin{array}{l}\text { End of } \\
\text { Q1 }\end{array}$ & 3 Months \\
\hline Return of Deposit & $\begin{array}{l}100 \% \\
\text { return }\end{array}$ & & $\begin{array}{l}50 \% \\
\text { return }\end{array}$ & $50 \%$ value of deposit \\
\hline Non-Compete Clause & No & & Yes & $\begin{array}{l}\text { Distributive - one either signs or does not. An interest } \\
\text { base approach might seek to quantify the duration and } \\
\text { negotiate on why the parties each need that }\end{array}$ \\
\hline
\end{tabular}

The process of setting anchors and defining the nature of the negotiations are useful for mediators to know, and to know as early as possible, to accurately generate a hypothesis about the dispute and to determine if it is indeed mediate-able.

\section{The Power of Anchors}

This anchor is one of the single most important indicators one party sends to the other in negotiations. Three significant things are worth noting here to help you understand the initial position or offer one party makes to the other in telling their story. Both sides usually adopt the 'OO effect' - the Opening Offer effect - they err on the side of caution in making their offer and leave themselves the widest possible trading space within a present range they have assessed to be their trading zone. Applying the "OO effect," the first offer is usually not the last. Why? Because it is not just a bid or a demand that suggests take it or leave it; there is an expectation of a trade. It is seen as an invitation to engage in a bargaining process. In the case above, the lessee may have predetermined that they would be willing to offer between $€ 50 \mathrm{k} \& € 63 \mathrm{~K}$ to exit the lease and the landlord, for example may well be willing to go as low as $€ 58$ (because he could quickly release the premises) when he is entitled under the contract to $€ 75$. This [€50-63 or €75-58] is known as 'a range' and in pre-mediation asking parties have they considered a figure other than their opening big number often sets the expectation that the first offer may not be palatable to the other side and that a backup position is a good alternative to the risk of having the talks break down. Therefore, anywhere between $€ 60 \mathrm{k} \& € 63 \mathrm{k}$ is the zone of potential agreement, the ZOPA. As each side negotiates into this zone it represents a willingness to settle. How do they get there? They move and trade, giving and getting- which is negotiating via bargaining. Also important to note is that these moves off of their initial anchors indicate their likely concession pattern. Each side will usually 'open' with a figure or anchor that maximizes their trading room. The landlord will start at $€ 75 \mathrm{k}$ and the 
lessee will start at $€ 50 \mathrm{k}$. These opening offers are not usually grasped out of the air; the parties often use 'reference points' to inform their figure. Reference points inform anchors. Understanding parties' reference points is very useful for mediators in helping the parties challenge the validity of the other's reference points. Take for example the lessee above who wants to buy out the lease of the building, typical reference points for them might be: the current price of leases in the area, the number of months left on the lease, the monthly cost of the lease, the opportunity cost of losing the new larger premises they are trying to move to, the legal costs associated with the move that he has already paid that will be a sunk cost if he can't negotiate his way out of the current lease. The reference points from the landlord's perspective are likely to be very different -the cost of replacing the tenant, the cost of the vacancy gap, the difference in revenue between the buy-out offer and the recurring income of the rent for the duration, the loan repayments, the income services, tax implications. Sometimes these anchors are quite extreme. The more extreme the anchor and the longer the party holds onto that anchor, as a right, the longer it will take to move from it - if at all. However, if the parties have considered a range before making an initial offer, there is a greater likelihood of movement toward a Zone of Agreement.

How does this information help mediator work more effectively with the parties? First, knowing the process of setting and defending an anchor gives the mediator a basis for inquiring about the parties' reference points. The reference points may provide an opening to explore interests, rather than dealing with an exchange of positions. Second, this information helps a mediator to support the trading dynamics in the room. If an anchor is extreme, the mediator may consider inviting the party to re-anchor - make a different offer. Alternatively, the mediator may ask the party to explain the demand, encouraging the party to explain where the data to support their demand is coming from. Depending on the response, the mediator may want to inquire about the nature and the source of this information in order to create the opportunity to reality test both parties' anchors. Third, remember, anchors are often self-serving and selfprotecting, they set the line of negotiation that you are hoping the parties will trade across later in the mediation and they are informed from the reference points that each party seeks to use, regardless of their validity.

One of the biggest (and earliest) challenges for the mediator is helping the parties decide who will anchor first. The first offer sets one point on the bargaining range. Too high and the other party may sense that the negotiation is futile. Too low, and the possibility of a settlement can be undermined. There is a Native American saying, 'you talk and talk until the talking starts'. When the anchors are set down on both sides, then the real talking starts and the real work of the mediator begins, mediate very effectively in helping the parties effectively negotiate. What I have found works best is to let the parties talk and describe and explain their anchors as a series of issues locked in the narrative of the story. Hearing each other's perspectives, aided by the mediator who may summarize the issues in dispute, ask clarifying questions or take other steps to assist the parties to understand one another may allow a discussion of interests and needs - not merely an exchange of positions.

Humans often classify information by comparison, benchmarks. Anchors are base figures from which negotiators add or subtract in a process of judging and exchanging offers. 
Research conducted by Dr. Margaret Neale shows that people consistently look for and rely on anchors in making judgments. (Neale \& Bazerman 1992). An anchor may be set by a previous transaction price, an industry standard or benchmark, a rumoured price, or a bid or offer. It may be drawn from thin air, but usually is not. Anchors matter. Because we want signposts and guides to help us with our judgments, we may be predisposed to focus on an anchor, even when that anchor has very little applicability to the current situation. Mediators must understand the importance of anchors in general, and how they are perceived by each of the parties. For a mediator when inviting the parties to describe the basis for their anchor, they can be instructed to reveal only what they feel is appropriate at this stage of the process so that they don't risk exposing too early their full underlying beliefs (and reference points) that shape that offer/bid; especially to a party who might reveal very little. Recognizing that negotiating is a process that involves numerous steps, the first of which may be issuing a demand (anchor), mediators can help parties move ahead at their own pace. Anchors matter. Though it may make no sense, parties often measure how far they have moved from their original anchor in negotiations to demonstrate their flexibility and responsiveness even if their anchor was extreme in the first place.

The important lessons for mediators about negotiations are: to become adept at helping parties determine their anchors and describe the nature of the demand; to understand their interests and needs behind them (reference points); to assess whether the differences in the anchors are "negotiable"- (the degree of the range [€50-€63] can be a good indicator of the degree of likely movement); and most importantly to know whether, when, and how to address the anchors.

\section{Two Types of Negotiation}

There are two approaches to negotiation - mindsets or theories: distributive and integrative. Distributive is an approach that, in simple terms, involves dividing a fixed sum or other object. The object of the negotiation is viewed as fixed, and an increase on one person's share necessarily means a reduction in the other person's portion. An integrative approach to negotiations is based on principles or beliefs, that allow for "integrating" other elements into the negotiation; sometimes viewed as pie swelling or value creation. With an integrative approach, parties consider how related items or objects can be brought into the negotiation.

In all negotiations parties must divide the resources (likely issues can include money, time, status, employment, services). If you think of the negotiation as a pie, distributive negotiations are those where the parties are concerned only with how a fixed-pie will be divided as a mind-set-a set of beliefs or values about the "pie." Distributive issues can only be resolved such that one person's gain is the other party's loss. If parties argue only over one issue, then it is a mathematical certainty that one will feel they have lost or lost more than the other. If we both want a share of a windfall that neither of us has an express right to, all we can do is figure out how to split it, to agree on some optimization for the maximum gain for ourselves, with the other side usually preventing us from taking it all. They would usually have to be very accommodating to allow us to do that and, at the start of a mediation, 
accommodation is not the dominant mode of either side as they seek to make the most of their argument and position. However, not all parties come to mediation with a distributive mind-set, many approach mediations with an integrative mind-set and this can aid the concession trading in mediation between the parties.

Distributive negotiations determine how a fixed pie will be divided. Sometimes if negotiations involve only one issue i.e. price, then the resource they are negotiating for is fixed and the negotiation is purely distributive. However, some things are too important to split - if both parents in a divorce settlement want their only child to be with them on Christmas day, they can't split the child so they can only then split the child's time. Distributive negotiations are also termed, rights based negotiations, valueclaiming - I take what is mine, usually a function of one sides level of assertiveness demonstrated in competitive behaviour or fixed pie negotiations.

Integrative Negotiations have the potential to expand the size of the pie available for the parties to divide. They are characterized by a win-win orientation. Integrative negotiations create value in two ways: firstly, by extending the range of issues in a negotiation to make the deal bigger and better and, secondly, by identifying or incorporating issues which the two sides value differently. When parties' value items differently they can make concessions on issues they value less in exchange for concessions on issues they value more. That increases the size of the pie for both parties. Integrative negotiations involve more than one issue (VARIABLE). Knowing what variable to include and how to value or price your variables and your opponent's variables allows parties, even the weaker party in the negotiation, to plan a trading pattern and successfully attain your objectives. Integrative negotiations are generally more complex. There are often more issues to deal with. But in that complexity lies the secret to an effective solution. This happens when the parties discuss the relative worth of their variables, and understand which are of major importance and which are less important. Some issues are more significant to one side and other issues are of lesser importance. Solutions emerge when parties are able to create agreements that address each person's most important issues.

Often in mediation parties come to us in a distributive mindset and through the process of mediation, the issues are mutualized, viewed from both sides, and in many instances there is relative worth in the issues - items that they both value differently. The more relative worth, the more tradeability, the greater the potential to negotiate. In effect, the process of mediation often helps parties to turn what started as a positional, distributive approach to the conflict into an integrative solution with enough issues on the table for both sides to get enough to satisfy them, as opposed to the win-lose concept they commenced the discussion with.

\section{The Skills of more Effective Negotiators}

"People will not negotiate with you unless they believe you can help them or hurt them." [Volkema 1999: 11]. Better negotiators are thoroughly prepared, are able to separate themselves (their egos) from the issues, while having genuine emotional engagement with the parties. Effective negotiators 
are also great listeners, clear communicators, able to build rapport with all parties, know their goals and limits and able to adapt their style to work with multiple personality types and different cultural contexts. Can you imagine a good mediator without any of these skills?

\section{The Process of Mediation and the Stages of Negotiation}

Whether one is negotiating an interpersonal dispute or conducting a commercial matter, although the process may vary slightly, the core concepts of negotiation described earlier in this paper remain consistent. In every negotiation there are initial exchanges of stories about the topics to be negotiated, then one party initiates the bargaining process by stating an offer, demand (or anchor), the other responds, then the negotiation proceeds with a serial exchange of proposals and explanations with a goal of finding terms of agreement that are mutually acceptable. In terms of process, however, one wellunderstood difference is that in a commercial context shuttle negotiations are more prevalent with the mediator moving between caucus rooms to discuss the issues and convening joint session for limited time periods. Whereas, in more traditional forms of mediation, the aim is to keep the parties in joint session in the belief that the parties to the conflict are best positioned to achieve a resolution that they can live up to.

\section{Managing the Dance of Negotiation}

"Any method of negotiating may be fairly judged by three criteria: it should produce a wise agreement if agreement is possible, it should be efficient, and it should improve or at least not damage the relationship between the parties." [Ury \& Fisher, 1982]. Mediation shares all three of these goals, along with others. A wise agreement, whether achieved through negotiation or mediation, can be defined as one that meets the legitimate interests of each side to the extent possible, resolves conflicting interests fairly, is durable and takes into account the interests of others who have been affected by the conflict and who have a concern for the outcome. Mediators' help parties negotiate to get the best outcome and assist parties to set aside expectations and pre-conceived ideas that may limit the options for securing a reasoned settlement. As research has shown, "all executives have pervasive decision making biases that blind them to opportunities and prevent them from getting the most out of the deal." [Bazerman and Neale, 1994]. Mediators help parties avoid the pitfalls of these biases by applying heuristic methods, inviting the parties to identify their preconceptions and their influence on the course of the negotiation. Then by helping to focus on the impact of these assumptions on the other party and encouraging them to mutualize the issue, mediators enable the parties to recognize their interdependence. Once this acknowledgment occurs, the parties can, instead of acting from only their self-interest, work towards their joint interest of achieving a positive outcome. One helpful technique used frequently by mediators is to assist parties move from positions to interests (reference points) by helping them engage with one another, to state and clarify their initial position, then assist them to explore the interests that underpin their position. Mediators do this via questioning, gathering data and helping to break down interests 
into needs, by listening attentively.

Another technique, applicable in negotiations and in mediation, used when parties get stuck and seem unwilling to move from their positions is to ask a simple question: What if? Using a hypothetical question can help parties refocus on their common objective-a solution-and fully consider the alternative solutions or alternatives if no settlement is achieved. When parties understand their options and alternatives to a negotiated settlement, namely their BATNA, best alternative to a negotiated agreement, it gives them power in a negotiation by inviting them to think about options. In other circumstances parties have to consider a WATNA, worst alternative to a negotiated agreement. For example, in the landlord lease dispute described earlier, if the parties can't find agreement they may revert to court and spend more (in time and money) fighting for their positions than the gap of the difference in their positions. A mediator should seek to ensure that all parties understand the alternatives open to them—both the best and the worst — to ensure that they make informed choices in their best interest.

\section{Conclusion}

Bruce Patton, Harvard Project Co-Founder stated, "I may not be able to make you negotiate my way but you can make me negotiate your way" (2005). The lesson for mediators is that the way in which one party negotiates can dominate or manipulate a process and force the other to do the same anchoring effect - you anchor high and go first, and though I was intending to offer a reasonable anchor, I adjust mine upwards as a result of the figure you picked. Being mindful of the tools and tactics of negotiation in the dynamics of conflict can help mediators ensure they are able to successfully manage the process and apply the dynamics of the 'negotiation conversation' in the mediation room. If as a mediator you don't understand the tectonic plates of the negotiation that are constantly moving, shaping the dance of trading, and one of your clients is aware of this process of movement, they may have a disproportionate ability to affect the outcome. Equally, if all of your clients do understand the dynamics and as mediator you do not, your ability to help manage the interactions could be seriously diminished. An understanding of negotiation in the context of mediation will enhance your skill set as a professional mediator by helping you to assist parties to move off their opening positions and trade their way to a more reasonable space where, without necessarily compromising the interests of the other party, their individual and shared interests and needs are met. We leave a little bit of us in everything we do, broaden your practice and sharpen your negotiation skills to enhance your tool set in the dynamic changing world of conflict resolution. It's a 'win-win-win' for you and your parties. 


\section{References}

Bazerman, M \& Neale., M (1994) 'Introduction to Rational Thinking in a Negotiation', Negotiating

Rationally, Simon and Schuster, pp 2.

Cialdini, R (2001) 'Harnessing the science of persuasion', Harvard Business Review, October 2001, Vol. 79, p92-79.

Hoffmann, D. A (2011) 'Mediation, Multiple Minds and the Negotiation' Harvard Law Review, Vol. 16, p 297.

Neale, M, Bazerman, M. (1992) 'Negotiating Rationally, the Power and Influence of the Negotiators' Frame Academy of Management Executive, Vol. 6 No. 2.

Patton, B (2005) in The Handbook of Dispute Resolution Program of Negotiation, Moffitt, M \& Bordone, RC (Eds), Jossey-Bass.

Ury, W, Fisher, R (1982) 'Getting to Yes’ Management Review, Feb 1982, Issue 2, p 16, 6p.

Volkema, R. J. (1999) 'Understanding Negotiations' The Negotiation Toolkit - how to get exactly what you want in any business or personal situation, AMA Publications pp 11.

Margaret Considine is a mediator and commercial mediator, a negotiator and management consultant who works with national and international organisations to resolve business challenges. A council member of the MII, and associate faculty member of NUIM and IMI, Margaret lectures to Masters Level on mediation, negotiation and conflict resolution in addition to multiple management topics. Margaret is the author of six published books. 